Article

\title{
Design of a Platelet-Mediated Delivery System for Drug-Incorporated Nanospheres to Enhance Anti-Tumor Therapeutic Effect
}

\author{
Jun-ichiro Jo, Tsubasa Emi and Yasuhiko Tabata *
}

check for

updates

Citation: Jo, J.-i.; Emi, T.; Tabata, Y. Design of a Platelet-Mediated

Delivery System for

Drug-Incorporated Nanospheres to

Enhance Anti-Tumor Therapeutic

Effect. Pharmaceutics 2021, 13, 1724.

https://doi.org/10.3390/

pharmaceutics13101724

Academic Editors: Yoshinobu

Takakura and Yusuke Sato

Received: 21 September 2021

Accepted: 14 October 2021

Published: 18 October 2021

Publisher's Note: MDPI stays neutral with regard to jurisdictional claims in published maps and institutional affiliations.

Copyright: (c) 2021 by the authors. Licensee MDPI, Basel, Switzerland. This article is an open access article distributed under the terms and conditions of the Creative Commons Attribution (CC BY) license (https:// creativecommons.org/licenses/by/ $4.0 /)$.
Laboratory of Biomaterials, Institute for Frontier Life and Medical Sciences, Kyoto University, 53 Kawara-cho Shogoin, Sakyo-ku, Kyoto 606-8507, Japan; jo@infront.kyoto-u.ac.jp (J.-i.J.); ind.chemi.tsubasa@gmail.com (T.E.)

* Correspondence: yasuhiko@infront.kyoto-u.ac.jp; Tel.: +81-75-751-4121

\begin{abstract}
The objective of this study is to construct a platelet-mediated delivery system for drugincorporated nanospheres. Nanospheres of poly(lactic-co-glycolic acid) (PLGA-NS) with different sizes and surface properties were prepared by changing the preparation parameters, such as the type of polymer surfactant, the concentration of polymer surfactant and PLGA, and the stirring rate. When incubated with platelets, PLGA-NS prepared with poly(vinyl alcohol) suppressed the platelet activation. Scanning electron microscopic and flow cytometry examinations revealed that platelets associated with PLGA-NS (platelet hybrids, PH) had a similar appearance and biological properties to those of the original platelets. In addition, the PH with PLGA-NS specifically adhered onto the substrate pre-coated with fibrin to a significantly great extent compared with PLGA-NS alone. When applied in an in vitro model of tumor tissue which was composed of an upper chamber pre-coated with fibrin and a lower chamber culturing tumor cells, the PH with PLGA-NS incorporating an anti-tumor drug were delivered to the tumor cells through the specific adhesion onto the upper chamber and, consequently, drug release from the upper chamber took place, resulting in the growth suppression of tumor cells. It is concluded that the drug delivery system based on PH is promising for tumor treatment.
\end{abstract}

Keywords: platelets; nanopsheres; drug delivery system; poly(lactic-co-glycolic acid); tumor

\section{Introduction}

Malignant tumors continue to be a major problem for the life of human beings. Among the main strategies for tumor treatment, chemotherapy has attracted much attention, because chemotherapy can compensate the shortcomings of surgical tumor treatment, such as tumor recurrent and metastasis. So far, various types of chemotherapeutic agents have been developed and used in clinical settings [1-3]. However, most chemotherapeutic agents have no inherent tumor targetability, which causes an adverse effect due to a high dose administration.

To improve the tumor targetability, drug delivery systems using nanospheres have been widely explored [4-6]. Since it is comparably easy to adjust the physicochemical properties of nanospheres, the spatial- and temporal-controlled drug delivery can be achieved. It is well recognized that the nanospheres with a diameter less than $100 \mathrm{~nm}$, and the coating with some water-soluble polymers, such as polyethylene glycol and hyaluronic acid, accumulate in the vascular-rich tumor tissue by so-called enhanced permeability and retention effect [7]. In addition, the surface modification with biological ligands enables nanospheres to deliver to the target tissue [8,9]. However, the targetability is still low because the nanospheres are often recognized by the reticuloendothelial system and eliminated from blood circulation in a short time period [10]. 
Recently, in addition to the materials-based system of drug delivery described above, a new drug targeting strategy by combining cells or their membrane, has increasingly attracted attention due to their inherent abilities, such as the minimal interaction with normal cells, the homing ability for desired cells, and the escape nature from immune surveillance. Various cell types of erythrocytes, leukocytes, platelets, and stem cells have been utilized for this strategy of drug delivery based on the natural cellular components [11-15]. Among them, the combination of platelets and their membrane is one of the most feasible strategies because it is expected that their innate functions can be applied for various vascular disorders (e.g., tumor, inflammation, thrombosis, and hemorrhage) [16-18]. It has been reported that there is a close relationship between the tumor malignancy and platelets [19]. Additionally, in tumor tissues, the active tumor invasion into tumor blood vessels causes a number of microhemorrhage (immature fibrin clot) [20,21]. Based on this knowledge, several studies on drug-loading platelets for tumor treatments have been reported, although the drug loaded is limited to only water-soluble drugs $[16,17,22]$.

The platelets physiologically play an important role in the removal of foreign materials from the blood circulation through uptake $[23,24]$. Based on this characteristic, there have been studies that reported on the internalization of latex particles and liposomes by platelets [23-26]. In this context, it can be hypothesized here that platelets could be a natural cell carrier for water-insoluble drug-loaded nanospheres aiming at natural targeting of tumor tissues. In the tumor tissues, inflammation reactions take place, leading to the subsequent deposition of fibrin. Platelets have an inherent ability for the adhesion to fibrin. Based on this mechanism, platelets naturally target to the tissues. Considering the application of platelets as the natural carrier of drugs, it should be noted that platelets have a unique characteristic of activation which can be observed by aggregation and degranulation to maintain their biological functions $[27,28]$. When activated, platelets lose their ability for targeting to the tumor tissue and materials uptake [29]. Therefore, to achieve the platelet application as the carrier of nanospheres loading water-insoluble drugs, it is highly required to design nanospheres which avoid the activation of platelets.

The objective of this study is to construct a platelet-mediated delivery system for nanospheres incorporating water-insoluble drugs (platelet hybrids, $\mathrm{PH}$ ), which enable drugs to specifically deliver to the target site and gradually release. In the present study, nanospheres of poly(lactic-co-glycolic acid) (PLGA-NS) with different sizes and surface properties were prepared for the optimization of nanospheres preparation conditions to minimize the platelet activation. After the incorporation of coumarin- 6 or paclitaxel of a water-insoluble anti-tumor drug into the PLGA-NS, the PH with the PLGA-NS were prepared to evaluate their biological functions. We examined the targetability to fibrin and anti-tumor effect of $\mathrm{PH}$ in an in vitro tumor tissue model.

\section{Materials and Methods}

\subsection{Reagents}

Poly(lactic-co-glycolic acid) (PLGA, the lactic acid/glycolic acid molar ratio $=75 / 25$, molecular weight $=20,000 \mathrm{Da}$ ), thrombin, and paclitaxel $(\mathrm{PTX})$ were purchased from Wako Pure Chemicals Industries, Ltd., Osaka, Japan. Poly(vinyl alcohol) (PVA, degree of polymerization $=1000$, degree of saponification $=86-90 \%$ ) was kindly supplied from Japan Vam \& Poval Co., Ltd., Osaka, Japan. Gelatins with isoelectric points of 5.0 (pI5) and 9.0 (pI9) and the weight-averaged molecular weight of 100,000 Da were kindly supplied from Nitta Gelatin Inc., Osaka, Japan. Cellmatrix ${ }^{\circledR}$ type I-P was purchased from Nitta Gelatin Inc., Osaka, Japan. Fibrinogen and adenosine 5'-diphosphate (ADP) were purchased from Sigma-Aldrich Inc., St. Louis, MO, USA. Bovine serum albumin (BSA) was purchased from Nacalai Tesque Inc., Kyoto, Japan. Coumarin-6 (CMR) was purchased from Tokyo Chemical Industry Co., Ltd., Tokyo, Japan. The reagents were used without further purification. 


\subsection{Preparation of PLGA Nanospheres}

PLGA nanospheres (PLGA-NS) were prepared by the conventional nano-precipitation method [30]. The acetone solution (1 mL) containing PLGA was added dropwise to an aqueous solution $(10 \mathrm{~mL})$ of polymer surfactant, PVA, pI5, and $\mathrm{pI}$, followed by stirring to form an oil-in-water emulsion. The emulsion was continuously stirred at room temperature to evaporate the residual acetone. In this study, various PLGA-NS with different sizes and surface properties (Table 1) were prepared by changing various preparation parameters. To change the size of PLGA-NS, the concentrations of PLGA and surfactant polymers, stirring rate, and ionic strength of aqueous phase were changed. Different polymer surfactants of PVA, pI5, and pI9 were used to change the surface properties of PLGA-NS. After evaporation, PLGA-NS were collected by the centrifugation of 14,000 rpm for $30 \mathrm{~min}$ at $20^{\circ} \mathrm{C}$ and resuspended in double distilled water. The procedure of centrifugation and resuspension was repeated 3 times. Then, the PLGA-NS were lyophilized and stored at $4{ }^{\circ} \mathrm{C}$ before use. In the preparation of PLGA-NS incorporating CMR (CMR-PLGA-NS) or PTX (PTX-PLGA-NS), the same preparation parameter and procedure as PVA $_{200}$ (Table 1) was used except for the addition of various amounts of CMR or PTX to acetone solution of PLGA before emulsification.

Table 1. Preparation and physicochemical properties of PLGA nanospheres.

\begin{tabular}{|c|c|c|c|c|c|c|c|c|c|c|c|}
\hline \multirow{3}{*}{$\begin{array}{c}\text { Code } \\
\mathrm{PVA}_{200}\end{array}$} & \multicolumn{4}{|c|}{ Preparation Condition } & \multicolumn{7}{|c|}{ Property } \\
\hline & \multirow{2}{*}{$\begin{array}{c}\begin{array}{c}\text { Surfactant } \\
(w / v \%)\end{array} \\
1\end{array}$} & \multirow{2}{*}{$\begin{array}{c}\text { PLGA } \\
(w / v \%)\end{array}$} & \multirow{2}{*}{$\begin{array}{c}\begin{array}{c}\text { Stirring Rate } \\
\text { (rpm) }\end{array} \\
800\end{array}$} & \multirow{2}{*}{$\begin{array}{c}\mathrm{NaCl} \\
(\mathrm{mM}) \\
-\end{array}$} & \multicolumn{3}{|c|}{$\begin{array}{c}\text { Apparent Size } \\
(\mathrm{nm})\end{array}$} & \multirow{2}{*}{$\begin{array}{l}\text { PDI }^{\mathbf{a}} \\
0.047\end{array}$} & \multicolumn{3}{|c|}{$\begin{array}{c}\text { Zeta Potential } \\
(\mathrm{mV})\end{array}$} \\
\hline & & & & & 220 & \pm & $0.93^{b}$ & & -0.77 & \pm & 0.16 \\
\hline $\mathrm{PVA}_{500}$ & 1 & 2 & 400 & 500 & 470 & \pm & 11 & 0.17 & -0.62 & \pm & 0.098 \\
\hline $\mathrm{PVA}_{700}$ & 4 & 4 & 400 & 1000 & 660 & \pm & 14 & 0.21 & -0.56 & \pm & 0.11 \\
\hline $\mathrm{pI}_{300}$ & 1 & 0.5 & 800 & - & 310 & \pm & 2.7 & 0.15 & -10 & \pm & 0.87 \\
\hline pI5 500 & 2 & 2 & 400 & - & 490 & \pm & 1.1 & 0.14 & -7.3 & \pm & 0.41 \\
\hline $\mathrm{pI} 5700$ & 2 & 4 & 400 & - & 600 & \pm & 29 & 0.16 & -7.8 & \pm & 1.1 \\
\hline $\mathrm{pI}_{300}$ & 1 & 0.5 & 1200 & - & 290 & \pm & 1.8 & 0.1 & -1.9 & \pm & 0.19 \\
\hline $\mathrm{pI}_{500}$ & 1 & 2 & 800 & - & 460 & \pm & 11 & 0.15 & -1.9 & \pm & 0.19 \\
\hline $\mathrm{pI}_{700}$ & 1 & 4 & 400 & - & 670 & \pm & 21 & 0.16 & -2.0 & \pm & 0.58 \\
\hline
\end{tabular}

${ }^{\mathrm{a}}$ Polydispersity index, ${ }^{\mathrm{b}}$ Mean $\pm \mathrm{SD}$.

\subsection{Characterization of PLGA-NS}

The PLGA-NS were suspended in $10 \mathrm{mM}$ phosphate-buffered saline solution (PBS, $\mathrm{pH}$ 7.4), and the apparent size of nanospheres was measured by dynamic light scattering (DLS, Zetasizer Nano-ZS, Malvern Instruments Ltd., Worcestershire, UK). On the other hand, the PLGA-NS were dissolved in $10 \mathrm{mM}$ phosphate buffer solution ( $\mathrm{pH}$ 7.4), and the zeta potential was measured by electrophoresis light scattering (ELS, Zetasizer Nano-ZS).

The amount of CMR incorporated into PVA 200 -PLGA-NS was calculated based on the fluorescent intensity of CMR (dimethyl sulfoxide (DMSO) of solvent as a blank) measured by the fluorescent spectrophotometer (SpectraMax i3x, Molecular Devices Japan Co., Ltd., Tokyo, Japan) with excitation and emission wavelengths of 390 and $470 \mathrm{~nm}$, respectively. The amount of PTX incorporated into PVA 200 -PLGA-NS was measured by the high-performance liquid chromatography (HPLC, Prominence LC-AT20, Shimadzu Corp., Kyoto, Japan) equipped with a reverse phase column of C18-MS-II $(15 \mathrm{~cm}$, Nacalai Tesque Inc., Kyoto, Japan). The mobile phase, water and acetonitrile, was delivered at $25^{\circ} \mathrm{C}$ at the flow rates of 0.35 and $0.65 \mathrm{~mL} / \mathrm{min}$, respectively. The PTX eluted was detected by the ultraviolet detector at the wavelength of $230 \mathrm{~nm}$. The area of each eluted peak was integrated and calculated for the PTX quantification (DMSO of solvent as a blank). The measurements were independently performed three times. 


\subsection{Platelet Isolation}

The blood from the vena cava of C57BL/6N mice (10- to 15-week-old, male, Shimizu Laboratory Supplies, Kyoto, Japan) was collected by the syringe containing acid-citratedextrose solution $\mathrm{B}(100 \mu \mathrm{L})$, followed by the transfer to a tube containing buffered glucose saline-citrate solution $(500 \mu \mathrm{L})$. The blood collected was centrifuged at $1600 \mathrm{rpm}$ for $5 \mathrm{~min}$ at $20^{\circ} \mathrm{C}$ to separate into hemocytes and platelet rich plasma (PRP), then the supernatant containing PRP was collected and centrifuged at $1000 \mathrm{rpm}$ for $5 \mathrm{~min}$ at $20^{\circ} \mathrm{C}$ to fully remove the hemocytes. Finally, the supernatant was centrifuged at $3600 \mathrm{rpm}$ for $5 \mathrm{~min}$ at $20^{\circ} \mathrm{C}$, and platelets were collected in the sediment. The platelets were resuspended in modified Tyrode's buffer ( $134 \mathrm{mM} \mathrm{NaCl}, 2.9 \mathrm{mM} \mathrm{KCl}, 0.34 \mathrm{mM} \mathrm{Na}_{2} \mathrm{HPO}_{4}, 1 \mathrm{mM} \mathrm{MgCl}$, $10 \mathrm{mM}$ HEPES, and $5 \mathrm{mM}$ D-glucose, $\mathrm{pH}$ 7.4). The number of platelets was counted by using the hemocytometer (WakenBtech Co., Ltd., Kyoto, Japan). The platelets prepared were used for further experiments within $3 \mathrm{~h}$.

\subsection{Effects of PLGA-NS on Platelet}

Each PLGA-NS $(100 \mu \mathrm{g})$ suspended in $1 \mathrm{~mL}$ of modified Tyrode's buffer was mixed with $10^{8}$ platelets. After $30 \mathrm{~min}$ incubation at $37^{\circ} \mathrm{C}$, the mixture was centrifuged at $3600 \mathrm{rpm}$ for $5 \mathrm{~min}$ at $20^{\circ} \mathrm{C}$, and platelet number was counted by the hemocytometer. The ADP and thrombin of agonists which bind platelet surface receptors were used to induce the platelet activation.

\subsection{Preparation of Platelet Hybrids}

PVA $_{200}$-PLGA-NS, CMR-PVA 200 -PLGA-NS or PTX-PVA 200 -PLGA-NS (Table 2) were used for the association with platelet. Various amounts of PLGA nanospheres suspended in $1 \mathrm{~mL}$ of modified Tyrode's buffer were mixed with $10^{8}$ platelets and incubated for $30 \mathrm{~min}$ at $37^{\circ} \mathrm{C}$. The mixture was centrifuged twice at $3600 \mathrm{rpm}$ for $5 \mathrm{~min}$ at $20^{\circ} \mathrm{C}$ to remove free PLGA-NS and resuspended in modified Tyrode's buffer to obtain platelet hybrids (PH).

Table 2. Physicochemical properties of drug-loaded PLGA nanospheres.

\begin{tabular}{|c|c|c|c|c|c|c|c|}
\hline \multirow{2}{*}{$\begin{array}{c}\text { Code } \\
\text { PVA }_{200}-\mathrm{PLGA}-\mathrm{NS}\end{array}$} & \multicolumn{3}{|c|}{$\begin{array}{c}\text { Apparent Size } \\
(\mathrm{nm})\end{array}$} & \multicolumn{3}{|c|}{$\begin{array}{l}\text { Zeta Potential } \\
(\mathrm{mV})\end{array}$} & \multirow{2}{*}{$\begin{array}{c}\begin{array}{c}\text { Loading } \\
\text { (wt } \%)\end{array} \\
-\end{array}$} \\
\hline & 220 & \pm & $0.93^{a}$ & -0.77 & \pm & 0.16 & \\
\hline CMR-PVA $_{200}$-PLGA-NS & 240 & \pm & 8.9 & -0.51 & \pm & 0.18 & 2.7 \\
\hline PTX-PVA 200 -PLGA-NS & 240 & \pm & 1.4 & -0.59 & \pm & 0.097 & 9.6 \\
\hline
\end{tabular}

To evaluate the amount of CMR-PVA 200 -PLGA-NS associated with platelets, the $\mathrm{PH}$ were lyophilized and dissolved in DMSO. The fluorescence intensity of CMR (DMSO solvent as a blank) was measured by the fluorescence spectrophotometer at excitation and emission wavelengths of 390 and $470 \mathrm{~nm}$, respectively. To evaluate the association behavior in one platelet level, the $\mathrm{PH}(10,000$ counts) associated with different amounts of CMR-PVA 200 -PLGA-NS were analyzed on FACSCanto II flow cytometer and Flowjo software (Becton, Dickinson and Company, Franklin Lakes, NJ, USA).

To visually confirm the internalization of CMR-PVA 200 -PLGA-NS into platelets, the $\mathrm{PH}$ prepared with CMR-PVA 200 -PLGA-NS were added to a glass bottom dish. The $\mathrm{PH}$ were mildly shaken for $30 \mathrm{~min}$ at room temperature and washed twice with modified Tyrode's buffer, followed by the observation by the confocal laser microscopy IX73/CSU-W1 (OLYMPUS Corp., Tokyo, Japan) after staining the platelets with an anti-CD41/61 antibody (emfret Analytics GmbH \& Co. KG., Würzburg, Germany).

To morphologically observe the appearance and aggregating behavior of $\mathrm{PH}$, the $\mathrm{PH}$ with PVA 200 -PLGA-NS or PTX-PVA 200 -PLGA-NS were added to the glass bottom dish. After $30 \mathrm{~min}$, the PH were washed twice with modified Tyrode's buffer at room temperature. Then, the samples were fixed with $2.5 \mathrm{wt} \%$ glutaraldehyde for $2 \mathrm{~h}$ and washed twice with PBS. Samples were dehydrated in ascending ethanol grades for 15 min each and chemically 
dried with hexamethyldisilazane (Sigma-Aldrich Inc., St. Louis, MO, USA) overnight. The bottom glass plates were cut out by the ultrasonic cutter (USW-334, Honda Electronics Co. Ltd., Aichi, Japan) and fixed on an aluminum support with carbon-adhesive glue and sputter-coated with Au-Pt (E-1010, Hitachi High Tech. Corp., Tokyo, Japan). The samples were observed using a scanning electron microscopy (SU-3500, Hitachi High Tech. Corp., Tokyo, Japan).

\subsection{Evaluation of Biological Properties of $P H$}

After the preparation of PH with $\mathrm{PVA}_{200}$-PLGA-NS or PTX-PVA 200 -PLGA-NS, the PH $\left(10^{7}\right.$ platelets in $100 \mu \mathrm{L}$ suspension) were mixed with $10 \mu \mathrm{L}$ of thrombin $(2 \mathrm{U} / \mathrm{mL})$. After $15 \mathrm{~min}$, the PH were stained with $5 \mu \mathrm{L}$ each of Phycoerythrin (PE)-labeled anti-CD41/61 antibody and Fluorescein isothiocyanate (FITC)-labeled anti-CD62P antibody (emfret Analytics GmbH \& Co. KG., Würzburg, Germany) for further 15 min at dark and room temperature. Then, the PH stained (10,000 counts) were analyzed on FACSCanto II flow cytometer and Flowjo software. The platelets incubated with naked PTX for $30 \mathrm{~min}$ at $37^{\circ} \mathrm{C}$ were also evaluated to investigate the inhibitory effect of platelet activation by PTX.

\subsection{Evaluation of PH Affinity for Collagen and Fibrin}

The glass bottom dish (Matsunami Glass Ind., Ltd., Osaka, Japan) was coated with different proteins of BSA, collagen (Cellmatrix ${ }^{\circledR}$ type I-P), and fibrinogen. Protein coating was performed by adding $2 \mathrm{~mL}$ of PBS solution containing protein $(0.1 \mathrm{mg} / \mathrm{mL})$ to the dishes and incubating overnight at $37^{\circ} \mathrm{C}$. In the case of fibrinogen, the dish was washed with PBS twice, followed by adding the thrombin solution $(1 \mathrm{U} / \mathrm{mL})$ and incubating for $1 \mathrm{~h}$ at $37^{\circ} \mathrm{C}$ for the conversion of fibrinogen to fibrin. The PH with CMR-PVA $200-\mathrm{PLGA}-$ NS were added onto the glass bottom dish pre-coated with each protein. After mild shaking for $30 \mathrm{~min}$ at room temperature, the dishes were washed twice with the modified Tyrode's buffer. The fluorescent images were taken by the fluorescent microscope (BZX700, Keyence Corp., Osaka, Japan). To evaluate the fluorescent intensity, six images were taken at random and analyzed using the computer program Image J (NIH Inc., Bethesda, MD, USA). The Integrated Density of whole images (IntDen) was used as the fluorescent intensity for comparison.

For time-lapse imaging, the platelets were further cultured in Roswell Park Memorial Institute (RPMI) 1640 Medium (Thermo Fisher Scientific Inc., Waltham, MA, USA) supplemented with $10 \mathrm{vol} \%$ bovine fetal calf serum (FCS, GE Healthcare Life Sciences HyClone Laboratories Inc., Logan, UT, USA) and $1 \mathrm{vol} \%$ penicillin and streptomycin (Nacalai Tesque Inc., Kyoto, Japan) at $37^{\circ} \mathrm{C}$ in a $5 \% \mathrm{CO}_{2}-95 \%$ air atmospheric condition. At predetermined time points, the medium was totally collected, and then the fresh medium was added for the investigation of CMR release profile. The amount of CMR released from platelet into medium was measured by the fluorescent spectrophotometer as described above.

\subsection{Evaluation of Drug Delivery by PH with PLGA-NS}

The upper Transwell ${ }^{\circledR}$ inserts (polycarbonate membrane with a pore size of $8.0 \mu \mathrm{m}$, Corning Inc., Corning, NY, USA) were coated with BSA, collagen, and fibrin as described above. Then, the PH with CMR-PVA $200-$ PLGA-NS were added onto the upper insert pre-coated and incubated for $30 \mathrm{~min}$ at $37^{\circ} \mathrm{C}$. After that, the inserts were washed with RPMI medium for three times and set on the bottom plate in which B16F10 cells (mouse melanoma cell line, RCB2630, provided by the RIKEN BRC through the National BioResource Project of the MEXT/AMED, Japan) were cultured for $24 \mathrm{~h}$. The B16F10 cells were cultured for further 3 days in RPMI medium supplemented with $10 \mathrm{vol} \% \mathrm{FCS}$ and $1 \mathrm{vol} \%$ penicillin and streptomycin at $37^{\circ} \mathrm{C}$ in a $5 \% \mathrm{CO}_{2}-95 \%$ air atmospheric condition. The medium was changed every day and the fluorescent images of B16F10 cells were taken by the fluorescent microscopy. Three images from each group were taken at random and analyzed using the computer program Image J. The Integrated Density of whole images was used as the fluorescent intensity for comparison. 
To investigate the anti-tumor effect of $\mathrm{PH}$ on the B16F10 cells, the same procedures as described above were performed except for using PTX-PVA 200 -PLGA-NS for the preparation of $\mathrm{PH}$. The number of B16F10 cells were counted every day by detaching with $0.25 \mathrm{wt} \%$ trypsin-containing $1 \mathrm{mM}$ ethylenediaminetetra acetic acid (EDTA) solution (Nacalai Tesque Inc., Kyoto, Japan).

\subsection{Statistical Analysis}

The data were expressed as the mean \pm standard deviation (SD). All the statistical analysis was performed using one-way analysis of variance (ANOVA) with a post-hoc Tukey-Kramer multiple comparison test; $p$-values less than 0.05 were considered to be statistically significant.

\section{Results}

\subsection{Preparation of PLGA-NS}

Various types of PLGA-NS were prepared by changing the preparation parameters, such as the types of surfactant polymers, PLGA concentration, stirring rate, and sodium chloride addition (Table 1). The zeta potential of PLGA-NS prepared was changed by using different types of surfactant polymers used. The size of PLGA-NS prepared became large as both the concentration of surfactant polymers or PLGA increased and the rate of stirring decreased. The addition of sodium chloride made the size of PLGA-NS large.

\subsection{Platelet Activation by PLGA-NS}

Figure 1 shows the number of platelets after incubation with PLGA-NS of different sizes prepared in the presence of various surfactants. The incubation with ADP or thrombin of agonists for platelet activation reduced the number of platelets although the extent of decrement for ADP was smaller than that for thrombin. In the same way, the number of platelets was significantly decreased by the addition of PLGA-NS prepared with $\mathrm{pI} 5$ and pI9. On the other hand, the incubation with PLGA-NS prepared with PVA did not affect the number of platelets. The PLGA-NS with a larger size tended to reduce the number of platelets to a great extent compared with smaller PLGA-NS. Based on the findings, the preparation condition of $\mathrm{PVA}_{200^{-}}$(Table 1) was used in the following experiments.

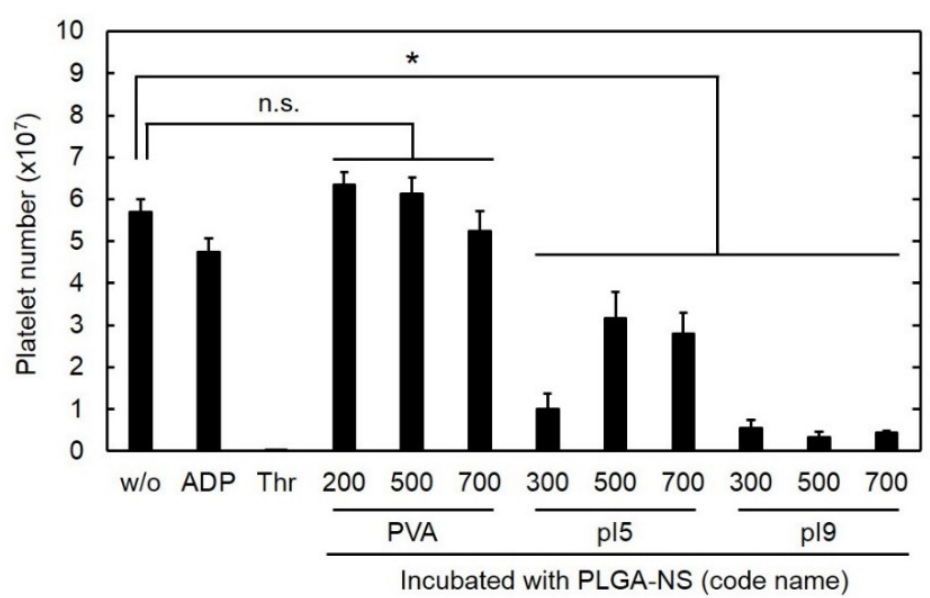

Figure 1. Number of platelets $30 \mathrm{~h}$ after incubation with PLGA-NS of different sizes prepared in the presence of various surfactants (PVA, pI5, and pI9). The ADP and thrombin (Thr) were used as agonists for platelet activation. n.s.: not significant. ${ }^{*} p<0.05$ : significant differences between two groups.

\subsection{Preparation of Drug-Loaded PLGA-NS}

Figure 2 shows the percentage of CMR or PTX loaded into PVA $_{200}$-PLGA-NS and the size as a function of the amount of drugs added. The percentage of drug loaded increased 
with an increase in the amount of drugs initially added (Figure 2A). The size of PLGANS became large when prepared with large amounts of drug initially added (Figure 2B). The drug-loaded $\mathrm{PVA}_{200}$-PLGA-NS with an apparent size of around $240 \mathrm{~nm}$ were used for further experiments (Table 2).

A

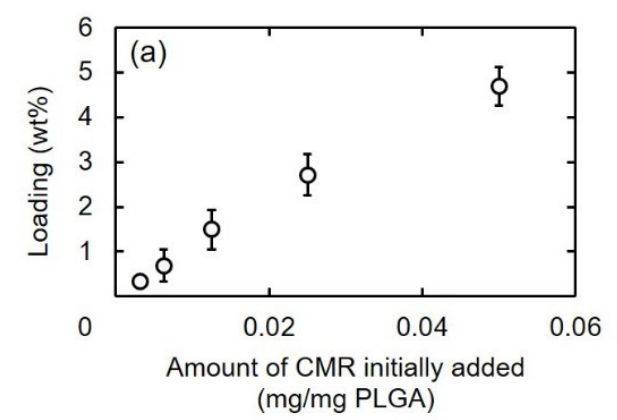

B

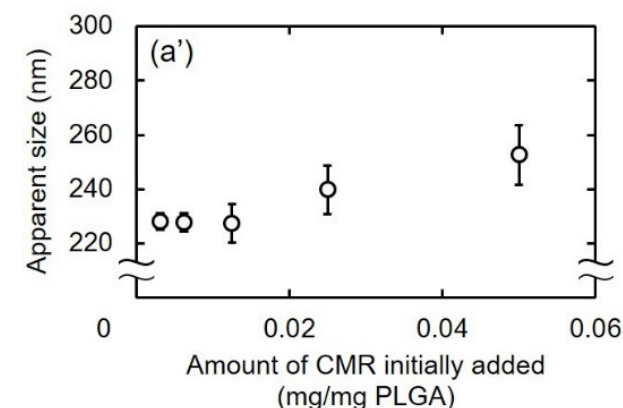

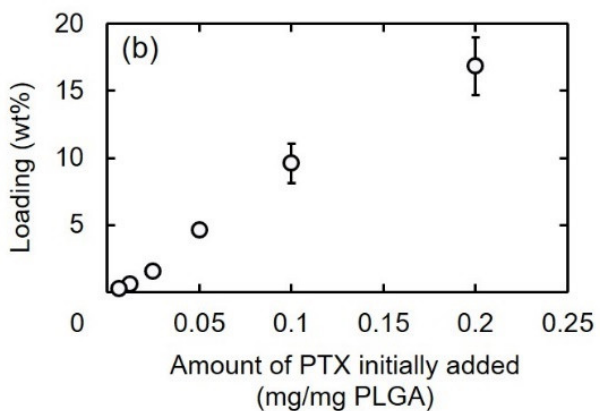

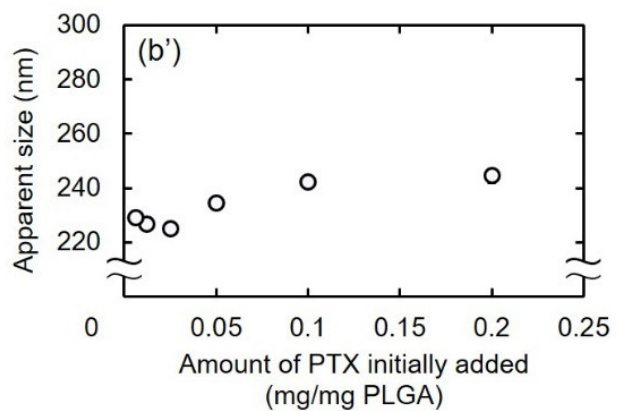

(mg/mg PLGA)

Figure 2. (A) Loading percentages of CMR (a) or PTX into PLGA-NS (b). (B) Apparent sizes of PVA $200-P L G A-N S$ incorporating CMR $\left(\mathbf{a}^{\prime}\right)$ or PTX $\left(\mathbf{b}^{\prime}\right)$. Various amounts of CMR or PTX were initially added for nanospheres preparation.

\subsection{Preparation of $\mathrm{PH}$}

Figure $3 \mathrm{~A}$ shows the amount of CMR-PVA $200-$ PLGA-NS associated with platelets. The amount increased with an increase in the amount of CMR-PVA 200 -PLGA-NS incubated. In the flow cytometric histograms, the peaks of $\mathrm{PH}$ shifted to a higher value of fluorescence intensity, while the peak attributed to CMR-PVA 200 -PLGA-NS was observed for the $\mathrm{PH}$ prepared by the association with $300 \mu \mathrm{g}$ of CMR-PVA $200-P L G A-N S$ (Figure 3B). Based on the results, the $\mathrm{PH}$ prepared with $100 \mu \mathrm{g}$ of CMR-PVA 200 -PLGA-NS was used for the following experiments.

When observed by the confocal laser microscopy, the platelets were co-localized with CMR-PVA $200-$ PLGA-NS (Figure 4A). From the SEM observation, no morphological change was observed for platelets or their hybrids prepared with PLGA-PVA $200-\mathrm{NS}$ or PTX-PVA 200 -PLGA-NS (Figure 4B).

\subsection{Activation Behavior of $\mathrm{PH}$}

Figure 5 shows the flow cytometric histograms of $\mathrm{PH}$ following the treatment with or without thrombin of an agonist for platelet activation. The PH prepared with $\mathrm{PVA}_{200}-\mathrm{PLGA}-$ NS and PTX-PVA 200 -PLGA-NS showed the similar histogram to the original platelets in terms of both CD41/61 and CD62P expressions. On the other hand, the platelet activation was inhibited by adding free PTX, followed by the stimulation with thrombin. 
A

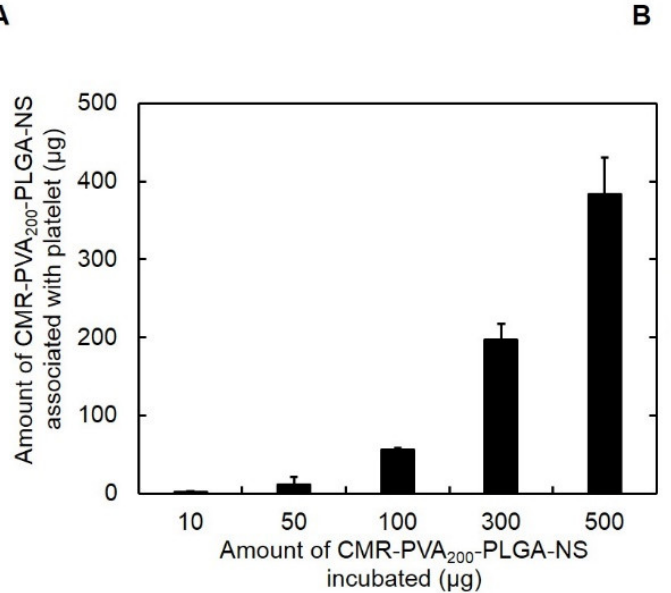

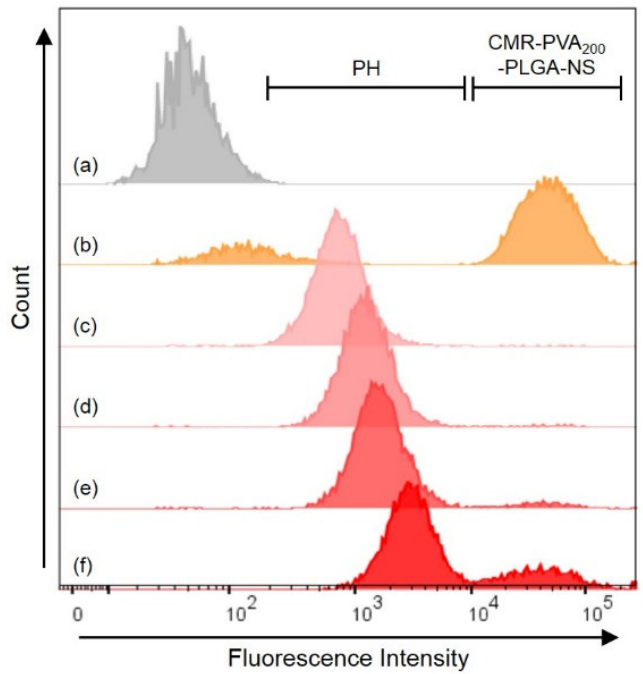

Figure 3. (A) The amount of CMR-PVA 200 -PLGA-NS associated with platelets $30 \mathrm{~min}$ after incubation with different amounts of CMR-PVA 200 -PLGA-NS. (B) Flow cytometric histograms of platelets (a), CMR-PVA $200-\mathrm{PLGA}-\mathrm{NS}$ (b), or PH obtained by incubation with 10 (c), 50 (d), 100 (e), or $300 \mu \mathrm{g}$ of CMR-PVA $200-$ PLGA-NS (f).

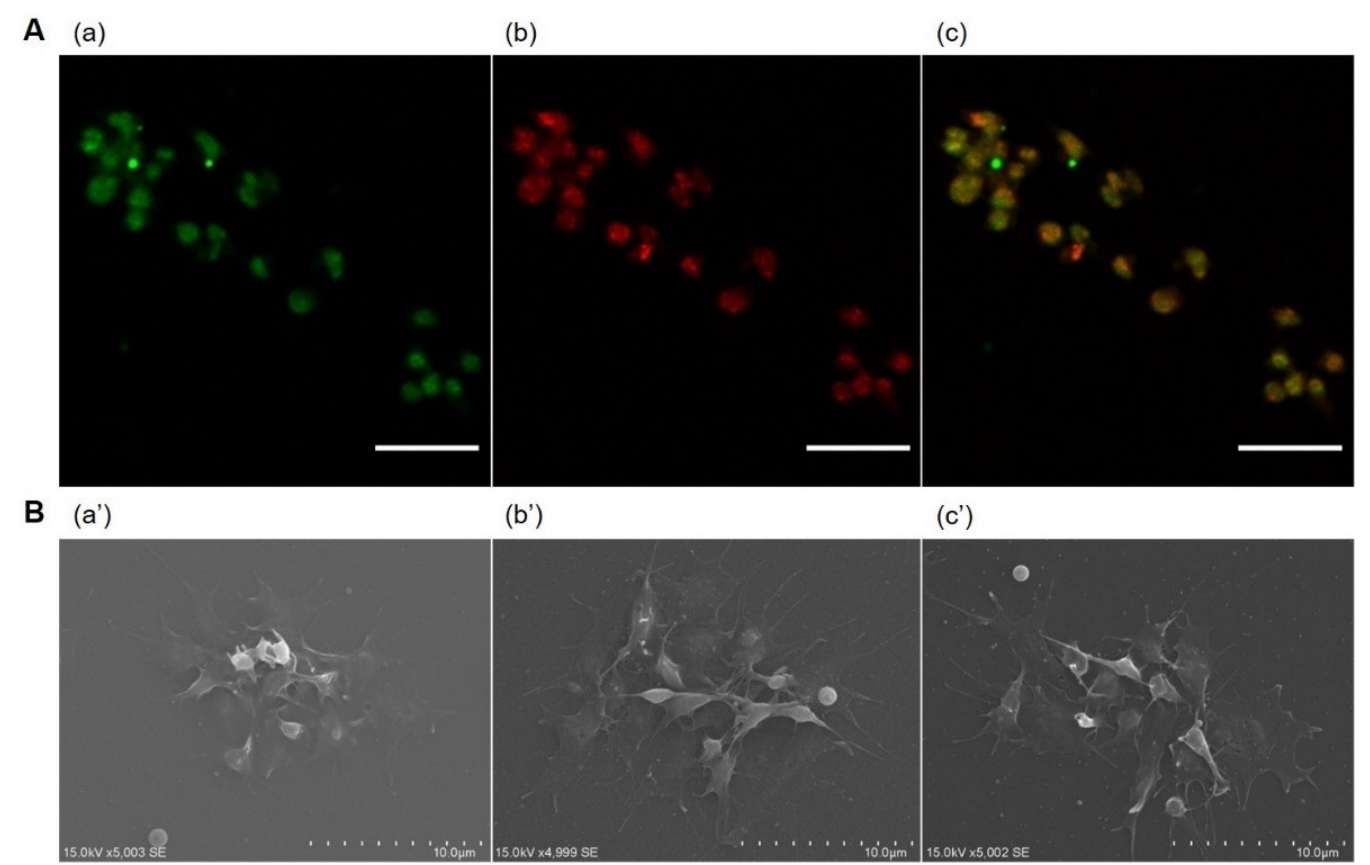

Figure 4. (A) Confocal microscopic images of PH incorporating CMR-PVA $200-P L G A-N S$. The PH were visualized by (a) CMR (green) incorporated into PVA $_{200}$-PLGA-NS and (b) the staining with anti-CD41/61 antibody (red), then the merged image was obtained (c). Scale bar is $10 \mu \mathrm{m}$. (B) Scanning electron microscopic images of platelets (a') or PH prepared by the incubation with PVA $_{200}$-PLGA-NS $\left(\mathbf{b}^{\prime}\right)$ or PTX-PVA 200 -PLGA-NS $\left(\mathbf{c}^{\prime}\right)$ aiming at the observation of aggregating behavior on the glass bottom dish. 

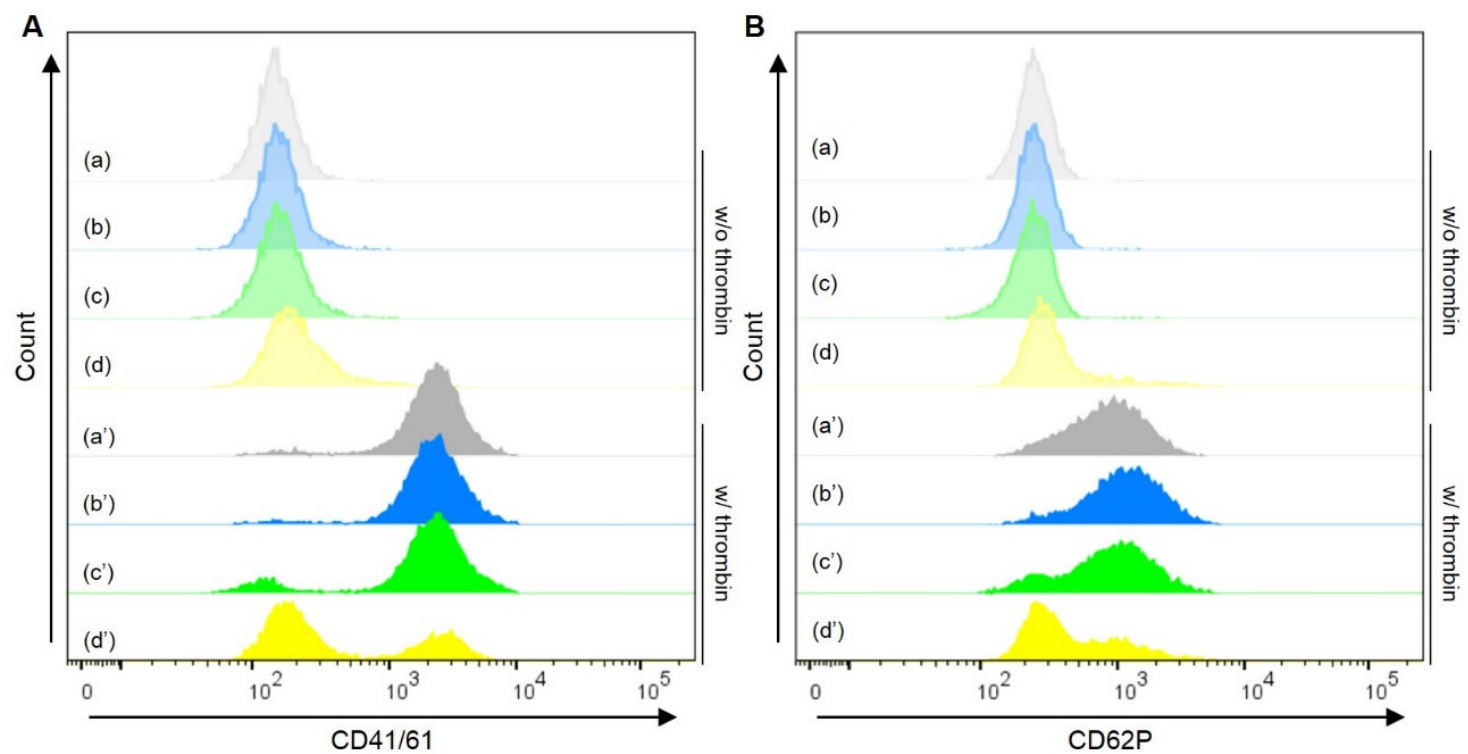

Figure 5. Flow cytometric histograms of platelets (a), PH with PVA $_{200}-$ PLGA-NS (b) or PTX-PVA $200-P L G A-N S$ (c), or platelets incubated with PTX (d) under the treatment without (blurred colors, a-d) or with thrombin (plain colors, $a^{\prime}-d^{\prime}$ ). The platelets or PH were stained with CD41/61 (A) or CD62P (B). The amount of PTX in the PH (c, $\left.\mathrm{c}^{\prime}\right)$ was same as that incubated with platelets $\left(\mathrm{d}, \mathrm{d}^{\prime}\right)$.

\subsection{Affinity of PH for Collagen and Fibrin}

Figure 6 shows the adhesion behavior of CMR-PVA 200 -PLGA-NS with or without hybrid by platelets. The CMR-PVA 200 -PLGA-NS hardly adhered to the glass pre-coated with BSA, collagen, and fibrin. On the contrary, the PH with CMR-PVA $200-P L G A-N S$ adhered to the glass or that pre-coated with collagen and fibrin. The adhesion of $\mathrm{PH}$ with CMR-PVA 200 -PLGA-NS was inhibited by the coating with BSA. The fluorescent intensity of PH with CMR-PVA $200-$ PLGA-NS adhered on the fibrin-coated glass was significantly higher than that of CMR-PVA 200 -PLGA-NS alone, while no difference was observed for the collagen-coated glass.
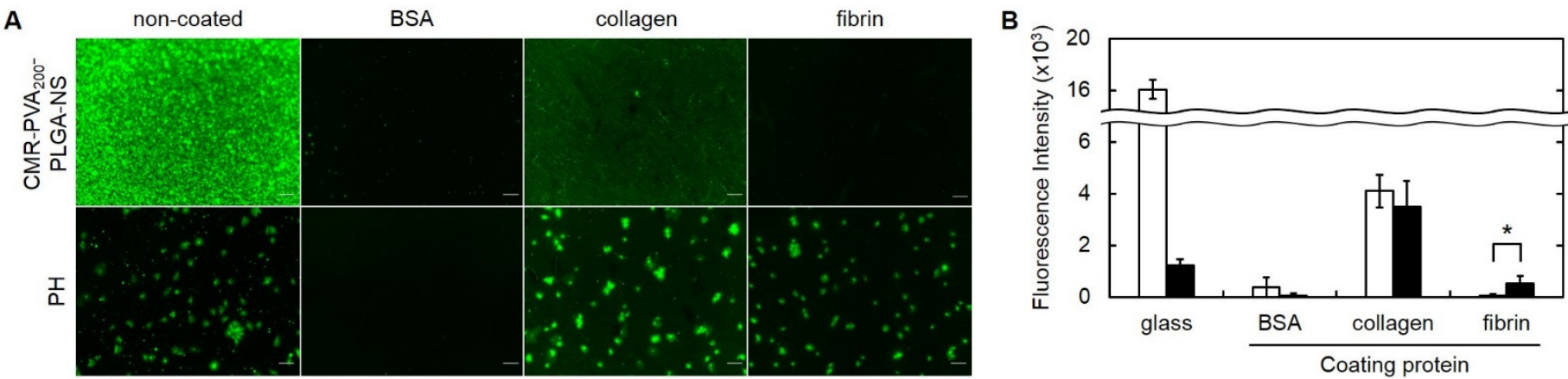

Figure 6. (A) Fluorescent microscopic images of $\mathrm{CMR}_{-\mathrm{PVA}} 200-\mathrm{PLGA}-\mathrm{NS}$ or their $\mathrm{PH}$ adhered on the bare glass bottom dish or the dish pre-coated with BSA, collagen, and fibrin. (B) The fluorescence intensity 30 min after adding $\mathrm{CMR}^{-P_{2 A}}{ }_{200}{ }^{-}$ PLGA-NS ( $\square$ ) or their PH adhered on the bare glass bottom dish or the dish pre-coated with proteins (BSA, collagen, or fibrin) (ם). Six images were analyzed by using ImageJ 1.53. ${ }^{*} p<0.05$ : significant difference between two groups.

\subsection{CMR-NS Release from $\mathrm{PH}$}

The release behavior of CMR-PVA $200-\mathrm{PLGA}-\mathrm{NS}$ from $\mathrm{PH}$ was evaluated by time-lapse fluorescent microscopic images (Figure 7). When observed by fluorescent microscopy, $\mathrm{CMR}_{\mathrm{PVA}} \mathrm{PO}_{20}$-PLGA-NS were released from platelet into the culture medium with time (Figure 7A). This phenomenon was quantitatively confirmed by measuring the CMR re- 
leased in the medium (Figure 7B). From the fluorescent observation at a high magnification, each platelet showed a rather brighter region inside initially and then the bright area decreased with time (Figure 7C).
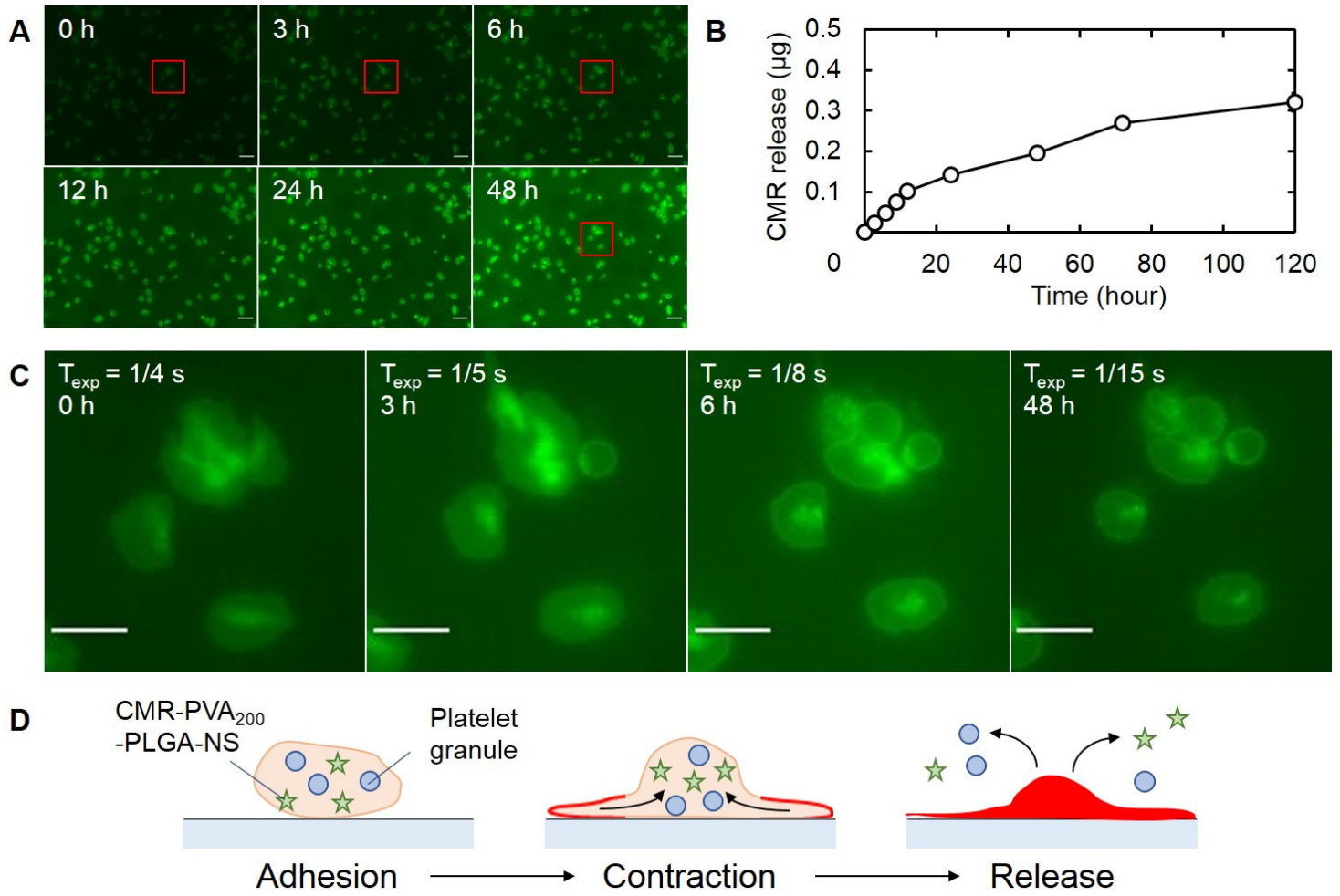

Figure 7. Time course of CMR-PVA 200 -PLGA-NS released from PH. (A) Time-lapse fluorescent microscopic images 0, 3, 6, 12, 24, and $48 \mathrm{~h}$ after incubation of PH. Scale bar is $10 \mu \mathrm{m}$. (B) Time profile of CMR release from PH. (C) Enlarged fluorescent microscopic images of red frame boxes indicated in (A). The values of $\mathrm{T}_{\text {exp }}$ indicates exposure time in the corresponding incubation periods. Scale bar is $5 \mu \mathrm{m}$. (D) The scheme of plausible mechanism on the release of CMR-PVA $200-P L G A-N S$ from $\mathrm{PH}$.

\subsection{Drug Delivery Profile of PH with PLGA-NS and In Vitro Anti-Tumor Effect}

Figure 8A shows the fluorescence microscopic images of B16F10 melanoma cells cultured on the lower chamber after the addition of CMR-PVA $200-P L G A-N S$ or their $\mathrm{PH}$ onto the upper Transwell ${ }^{\circledR}$ chamber pre-coated with various proteins. Little fluorescence was observed for the addition of CMR-PVA 200 -PLGA-NS on the upper chamber pre-coated with BSA or fibrin. On the contrary, a bright fluorescence was observed for $\mathrm{PH}$ with $\mathrm{CMR} \mathrm{PVA}_{200}$-PLGA-NS in adding on the upper chamber pre-coated with collagen or fibrin. A significant difference of fluorescent intensity in the image analysis was observed between $\mathrm{CMR}^{-P V A} \mathrm{~A}_{200}$-PLGA-NS and their PH only when using the upper chamber pre-coated with fibrin (Figure 8 B). Figure 8 C shows the time profiles of B16F10 cells number cultured on the lower chamber after the addition of platelet, PTX-PVA 200 -PLGA-NS, or their PH onto the upper chamber pre-coated with fibrin. The increment of cell number was significantly inhibited by the addition of PH with PTX-PVA 200 -PLGA-NS. 
A

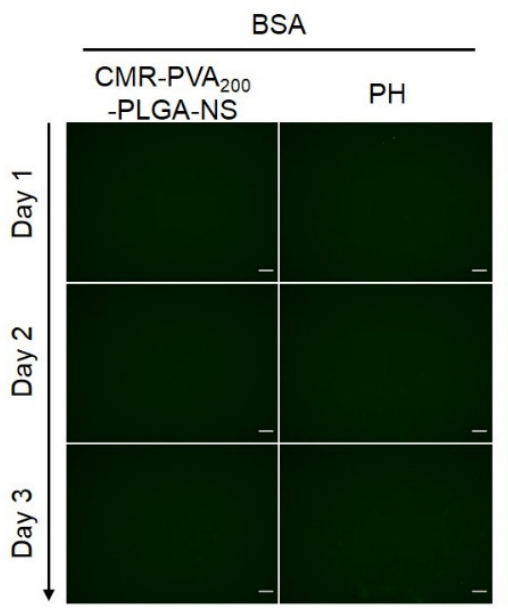

B

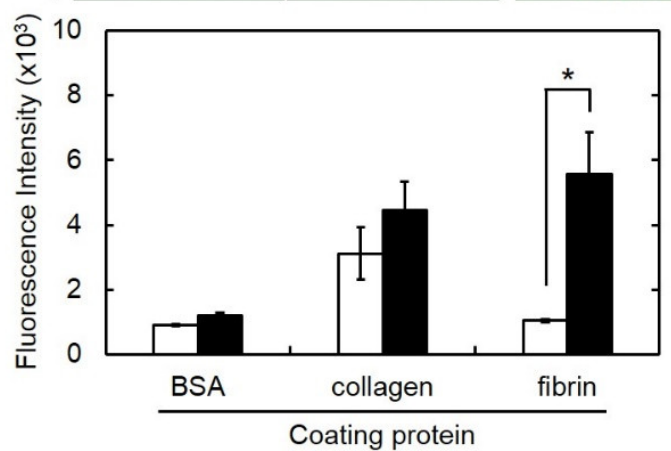

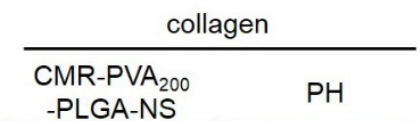
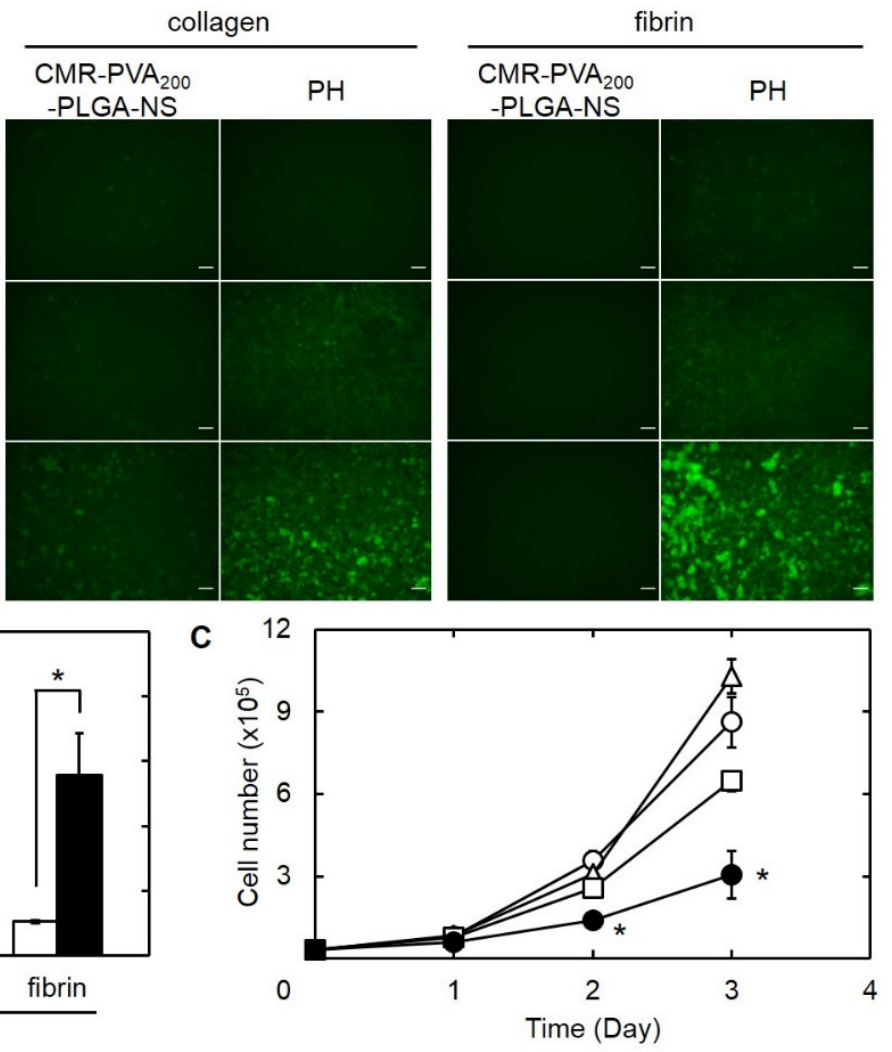

Figure 8. (A) Fluorescence microscopic images of B16F10 melanoma cells during 3 days of culture on the lower chamber inserted with the upper Transwell ${ }^{\circledR}$ chamber pre-coated with BSA, collagen, or fibrin, followed by the culture with CMRPVA $_{200}$-PLGA-NS or their PH on day 0. Scale bar is $100 \mu \mathrm{m}$. (B) Fluorescence intensity of CMR in B16F10 cells 3 days after culture on the lower chamber inserted with the upper Transwell ${ }^{\circledR}$ chamber pre-coated with BSA, collagen, or fibrin, followed by the culture with CMR-PVA $200-\mathrm{PLGA}-\mathrm{NS}(\square)$ or their PH on day 0 (ם). ${ }^{*} p<0.05$ : significant difference between two groups. (C) Time profiles of B16F10 cells number cultured on the lower chamber inserted with the upper Transwell ${ }^{\circledR}$ chamber pre-coated with fibrin, followed by the culture without $(\bigcirc)$ or with platelet $(\triangle)$, PTX-PVA 200 -PLGA-NS $(\square)$, and their PH on day $0(\bullet)$. The amount of PTX incorporated in each group (PTX-PVA $200-\mathrm{PLGA}-\mathrm{NS}$ or PH) is $5.5 \mu \mathrm{g}$. ${ }^{*} p<0.05$ : significant difference against other groups at the corresponding time.

\section{Discussion}

The present study demonstrates that a drug targeting system was achieved by the incorporation of drug into PLGA nanospheres and the subsequent association with platelets to form a PH. When applied for an in vitro tumor tissue model where tumor cells are separately combined with the insert pre-coated with the fibrin, the PH with PLGA nanospheres incorporating PTX enabled to suppress the growth of tumor cells through the specific adhesion to fibrin and the controlled release of the anti-tumor drug from the PLGA-NS.

For the efficient platelet-mediated drug targeting, it is highly required to associate drugs without any activation of platelets. It is well known that drugs sometimes affect the biological function of platelets through direct interaction. For example, the PTX itself suppresses the biological function of platelets [31]. Therefore, the incorporation of drugs into nanospheres without any induction of platelet activation is one of the practical ways to solve this issue. In the present study, first the effect of physicochemical properties of PLGA nanospheres (PLGA-NS) on the platelet activation was examined.

PLGA-NS with different sizes and surface properties were prepared by changing the type of polymer surfactant, the concentration of polymer surfactant and PLGA, and the stirring rate in preparation (Table 1). In the case of preparation in the PLGA-NS coated with PVA, the addition of sodium chloride was required to prepare the nanospheres with 
a large size. This can be explained by a high viscosity of the solution which affects the diffusion coefficient of organic solvents [32].

It was apparent from Figure 1 that the number of platelets did not change by adding PLGA-NS prepared with PVA, whereas it significantly decreased for PLGA-NS prepared with $\mathrm{pI} 5$ and $\mathrm{pI} 9$ gelatins. The platelet number decreased associated with the platelet aggregation induced by the activation as shown in the addition of ADP or thrombin. Therefore, this result clearly indicates that the surface property of nanospheres affects the platelet activation. It has been reported that nanospheres of metal, silica, lipid, and polymers activate the platelets in vitro or in vivo [33-36]. It is known that the glycoprotein VI of platelet membrane binds to the collagen's repeated sequence of glycine-proline-hydroxyproline and subsequently forms a triple helix structure, resulting in the platelet activation $[37,38]$. Although both pI9 and pI5 gelatins are a denatured form of collagen, pI5 gelatin is processed with alkaline for a longer period of time compared with pI9 gelatin. It is likely that the structure of pI9 is similar to that of the original collagen compared with pI5 gelatin. Thus, we can say with certainty that the difference in the decreased extent of platelet number may be due to the secondary structure of gelatin used in the preparation of PLGA-NS. The decreased extent of platelet number also depended on the size of PLGA-NS prepared with PVA. This is because large PLGA-NS with more than $500 \mathrm{~nm}$ in diameter disrupt the plasma membrane of platelets, resulting in a decrease in the number after mixing [23].

The size of PVA $_{200}$-PLGA-NS incorporating CMR or PTX tended to increase with an increase in the amount of CMR or PTX initially added (Figure 2). This is because a large amount of CMR or PTX with a water-insoluble nature located on the surface of PVA $_{200^{-}}$ PLGA-NS, resulting in the aggregation of nanospheres to each other via the hydrophobic interaction [39].

The fluorescent spectroscopic analysis revealed that platelets could associate with CMR-PVA 200 -PLGA-NS while the extent depended on the initial addition of nanospheres (Figure 3A). In addition, the flow cytometric analysis revealed that a part of CMR-PVA $200^{-}$ PLGA-NS was not associated and present outside the platelet when the high amount of nanospheres was used for association with platelets (Figure 3B). This result clearly indicates that the maximum amount of nanospheres exists for the association with platelets. In addition, it was technically difficult to separate the excess nanospheres from $\mathrm{PH}$ only by centrifugation. Therefore, in the present study, $100 \mu \mathrm{g}$ of $\mathrm{PVA}_{200}$-PLGA-NS was used to prepare the PH. Theoretically calculated, the number of CMR-PVA $200-\mathrm{PLGA}-\mathrm{NS}$ associated with one platelet is estimated to be from 10 to 100. The association between platelet and $\mathrm{CMR} \mathrm{PVA}_{200}$-PLGA-NS was also confirmed by the confocal laser microscopy (Figure 4A). However, the detailed site of CMR-PVA 200 -PLGA-NS associated with platelets is unclear at present. The combination of a specific and stable labeling method of platelets and a microscopic system with a higher resolution may resolve this issue. It is apparent from Figure 4B that the presence of $\mathrm{PVA}_{200}-\mathrm{PLGA}-\mathrm{NS}$ or PTX-PVA $200-\mathrm{PLGA}-\mathrm{NS}$ did not affect the morphology and aggregation behavior of platelets. Taken together, it is clearly demonstrated that the association of platelets without activation was achieved by making use of the PLGA-NS prepared with PVA. The PLGA-NS prepared with PVA did not induce the platelet activation. One of plausible reasons to be considered is a weak interaction strength between the PVA on the PLGA-NS surface and the components of platelets surface. However, a certain degree of interaction should be required for the association of nanospheres with platelets. At present, there is no explanation to interpret this contradiction point.

It is reported that PTX inhibits the activation of platelets due to the stabilization of platelet cytoskeleton [26]. Similar behavior was observed in that the activation of platelets incubated with free PTX was inhibited even after adding thrombin of an activation agent (Figure $\left.5 \mathrm{~A}\left(\mathrm{~d}^{\prime}\right), \mathrm{B}\left(\mathrm{d}^{\prime}\right)\right)$. On the other hand, the activation after adding thrombin was observed for PH with PVA $_{200}$-PLGA-NS incorporating PTX (Figure $5 A\left(a^{\prime}-c^{\prime}\right), B\left(a^{\prime}-c^{\prime}\right)$ ). This result clearly demonstrated that the incorporation into $\mathrm{PVA}_{200}$-PLGA-NS enables to maintain the biological function of platelets even after the association. The PH with PTX-PVA $200-$ PLGA-NS after adding thrombin slightly inhibited the activation (Figure $5 \mathrm{~A}\left(\mathrm{c}^{\prime}\right), \mathrm{B}\left(\mathrm{c}^{\prime}\right)$ ). It is 
possible that a small amount of PTX was released from PVA $200-$ PLGA-NS inside the platelet, resulting in the inhibition of activation after even adding thrombin.

To demonstrate the feasibility of a targeting system based on $\mathrm{PH}$ for anti-tumor therapy, it is necessary to experimentally confirm the specific interaction of $\mathrm{PH}$ with target molecules and the consequent drug release. In this study, collagen and fibrin were selected as target molecules because the platelets have an inherent affinity for the molecules [40-44]. In tumor tissues, inflammation continuously takes place which often damages the blood vessel. With the vessel damage, collagen is exposed on the inner surface of blood vessels. Platelets have an inherent affinity for the collagen exposed [45]. In addition, the continuous bleeding in the tumor tissue often allows fibrin to deposit there. The platelets also adhere the fibrin specifically for blood clotting [46]. As expected, the $\mathrm{PH}$ specifically adhered onto the glass surface pre-coated with collagen and fibrin (Figure 6A). In addition, the quantitative analysis revealed that the $\mathrm{PVA}_{200}$-PLGA-NS showed a specific affinity for fibrin through the platelet association to a great extent compared with that for collagen (Figure 6B). Taken together, it is expected that the $\mathrm{PH}$ would be a feasible cargo for the tumor targeting of $\mathrm{PVA}_{200}$-PLGA-NS in vivo. Once the PH is localized in the tumor tissue, the drug should be released to act on tumor cells to exert the anti-tumor effects.

The time-lapse fluorescent imaging experiment (Figure 7A,B) revealed that the CMR as a model drug was gradually released from the platelets with time. In addition, in the fluorescent dynamics of CMR inside the platelet (Figure 7C), it was found that at first the CMR-PVA 200 -PLGA-NS was accumulated to one region to show a bright fluorescence, and then the shape of the region was changed, followed by a decreased fluorescent intensity. This observation suggests that the platelet actively released nanospheres out as illustrated in Figure 7D. It is well known that platelets release the platelet granules over activation [47]. Taken together, it is likely that the CMR-PVA $200-\mathrm{PLGA}-\mathrm{NS}$ were released after the activation of platelets. However, it should be noted that all of the CMR-PVA ${ }_{200}-\mathrm{PLGA}-\mathrm{NS}$ were not always released from the platelets during the experimental period. The illustration of Figure 7D shows one possibility and other behaviors will be considered.

There are various types of cells and extracellular matrix in the tumor tissue. In the present study, a Transwell ${ }^{\circledR}$ system was used to mimic the in vivo environment of tumor tissue where the tumor cells are present separating from the extracellular matrix. The upper chamber pre-coated with fibrin or collagen and the lower chamber where the tumor cells are cultured were combined in the Transwell ${ }^{\circledR}$ system, then the natural affinity of PH for collagen and fibrin and the anti-tumor effect of $\mathrm{PH}$ were investigated by applying the $\mathrm{PH}$ onto the upper chamber. The $\mathrm{PH}$ were specifically delivered to the tumor tissue separating from the upper chamber pre-coated with fibrin while the growth of tumor cells was significantly suppressed (Figure 8C). This result clearly indicates that the $\mathrm{PH}$ were specifically adhered onto the upper chamber through the platelet-molecule interaction. Then, the PTX incorporated into PVA 200 -PLGA-NS would be released from platelets, and the PTX released was delivered to tumor cells. In other words, the incorporation into PVA $_{200}$-PLGA-NS allowed PTX to reduce the inherent toxicity for platelets and specifically deliver to tumor cells by the assistance of platelet inherent abilities for fibrin and release out of PTX from the PVA 200 -PLGA-NS uptaken. In the present study, where and how the PTX is released could not be clearly confirmed. In addition, the extent of PTX delivered to tumor cells was not quantitatively evaluated, either. These points should be investigated to make clear the detailed mechanism of the anti-tumor effect.

In future research, this platelet-mediated drug delivery system should be applied to in vivo experiments. It is well recognized that platelets have an affinity for the tumor stroma. Based on the research of "cancer stromal targeting (CAST)" therapy, an animal model of pancreatic cancers was considered to evaluate the anti-tumor effect [40]. In addition, it is known that platelets also have an ability to accumulate in inflamed vessels and tissues [48-50]. This platelet-mediated drug delivery system will be also applied to inflammatory diseases. 
Authors should discuss the results and how they can be interpreted from the perspective of previous studies and of the working hypotheses. The findings and their implications should be discussed in the broadest context possible. Future research directions may also be highlighted.

\section{Conclusions}

By adjusting the parameters in preparation, PLGA-NS with different sizes and surface properties were prepared with surfactant polymers. The PLGA-NS prepared with PVA did not induce platelet activation which is a practical problem to be resolved in the construction of $\mathrm{PH}$. The $\mathrm{PVA}_{200}$-PLGA-NS were expectedly associated with platelets by the simple incubation and separation. In addition, the presence of a PVA ${ }_{200}$-PLGA-NS incorporating drug did not affect any biological functions of platelets. As expected, the $\mathrm{PH}$ actively released $\mathrm{PVA}_{200}$-PLGA-NS incorporating drugs after they adhered to the fibrin-coated surface. The drugs released from platelets were specifically delivered to tumor cells and showed the in vitro suppression of tumor growth.

Author Contributions: Conceptualization, Y.T.; methodology, J.-i.J., T.E. and Y.T.; validation, J.-i.J., T.E. and Y.T.; formal analysis, J.-i.J., T.E. and Y.T.; investigation, T.E.; resources, Y.T.; data curation, T.E.; writing—original draft preparation, J.-i.J. and T.E.; writing—review and editing, J.-i.J. and Y.T.; visualization, J.-i.J. and T.E.; supervision, Y.T.; project administration, Y.T.; funding acquisition, Y.T. All authors have read and agreed to the published version of the manuscript.

Funding: This research was funded by the Japan Society for the Promotion of Science (JSPS) Grantin-Aid for Challenging Research (Exploratory), grant number JP18K19919.

Institutional Review Board Statement: The study was approved by the Institutional Animal Experiment Review Board of the Institute for Frontier Life and Medical Sciences, Kyoto University (protocol code F-17-213 and date of approval 1 April 2017).

Informed Consent Statement: Not applicable.

Conflicts of Interest: The authors declare no conflict of interest.

\section{References}

1. Aparicio-Blanco, J.; Sanz-Arriazu, L.; Lorenzoni, R.; Blanco-Prieto, M.J. Glioblastoma chemotherapeutic agents used in the clinical setting and in clinical trials: Nanomedicine approaches to improve their efficacy. Int. J. Pharm. 2020, 581, 119283. [CrossRef] [PubMed]

2. Dhupal, M.; Chowdhury, D. Phytochemical-Based Nanomedicine for Advanced Cancer Theranostics: Perspectives on Clinical Trials to Clinical Use. Int. J. Nanomed. 2020, 15, 9125-9157. [CrossRef] [PubMed]

3. Fraguas-Sanchez, A.I.; Martin-Sabroso, C.; Fernandez-Carballido, A.; Torres-Suarez, A.I. Current status of nanomedicine in the chemotherapy of breast cancer. Cancer Chemother. Pharmacol. 2019, 84, 689-706. [CrossRef] [PubMed]

4. Majumder, J.; Taratula, O.; Minko, T. Nanocarrier-based systems for targeted and site specific therapeutic delivery. Adv. Drug. Deliv. Rev. 2019, 144, 57-77. [CrossRef] [PubMed]

5. Cai, S.S.; Li, T.; Akinade, T.; Zhu, Y.; Leong, K.W. Drug delivery carriers with therapeutic functions. Adv. Drug Deliv. Rev. 2021, 176, 113884. [CrossRef] [PubMed]

6. Perrigue, P.M.; Murray, R.A.; Mielcarek, A.; Henschke, A.; Moya, S.E. Degradation of Drug Delivery Nanocarriers and Payload Release: A Review of Physical Methods for Tracing Nanocarrier Biological Fate. Pharmaceutics 2021, 13, 770. [CrossRef] [PubMed]

7. Matsumura, Y.; Maeda, H. A new concept for macromolecular therapeutics in cancer chemotherapy: Mechanism of tumoritropic accumulation of proteins and the antitumor agent smancs. Cancer Res. 1986, 46, 6387-6392. [PubMed]

8. Ahmed, A.; Sarwar, S.; Hu, Y.; Munir, M.U.; Nisar, M.F.; Ikram, F.; Asif, A.; Rahman, S.U.; Chaudhry, A.A.; Rehman, I.U. Surface-modified polymeric nanoparticles for drug delivery to cancer cells. Expert Opin. Drug Deliv. 2021, 18, 1-24. [CrossRef] [PubMed]

9. Guido, C.; Maiorano, G.; Cortese, B.; D'Amone, S.; Palama, I.E. Biomimetic Nanocarriers for Cancer Target Therapy. Bioengineering 2020, 7, 111. [CrossRef] [PubMed]

10. Gref, R.; Minamitake, Y.; Peracchia, M.T.; Trubetskoy, V.; Torchilin, V.; Langer, R. Biodegradable long-circulating polymeric nanospheres. Science 1994, 263, 1600-1603. [CrossRef]

11. Zarrin, A.; Foroozesh, M.; Hamidi, M. Carrier erythrocytes: Recent advances, present status, current trends and future horizons. Expert Opin. Drug Deliv. 2014, 11, 433-447. [CrossRef]

12. Xue, J.; Zhao, Z.; Zhang, L.; Xue, L.; Shen, S.; Wen, Y.; Wei, Z.; Wang, L.; Kong, L.; Sun, H.; et al. Neutrophil-mediated anticancer drug delivery for suppression of postoperative malignant glioma recurrence. Nat. Nanotechnol. 2017, 12, 692-700. [CrossRef] 
13. Ye, B.; Zhao, B.; Wang, K.; Guo, Y.; Lu, Q.; Zheng, L.; Li, A.; Qiao, J. Neutrophils mediated multistage nanoparticle delivery for prompting tumor photothermal therapy. J. Nanobiotechnol. 2020, 18, 138. [CrossRef]

14. Levy, O.; Zhao, W.; Mortensen, L.J.; Leblanc, S.; Tsang, K.; Fu, M.; Phillips, J.A.; Sagar, V.; Anandakumaran, P.; Ngai, J.; et al. mRNA-engineered mesenchymal stem cells for targeted delivery of interleukin-10 to sites of inflammation. Blood 2013, 122, e23-e32. [CrossRef] [PubMed]

15. Hu, C.M.; Fang, R.H.; Wang, K.C.; Luk, B.T.; Thamphiwatana, S.; Dehaini, D.; Nguyen, P.; Angsantikul, P.; Wen, C.H.; Kroll, A.V.; et al. Nanoparticle biointerfacing by platelet membrane cloaking. Nature 2015, 526, 118-121. [CrossRef] [PubMed]

16. Xu, P.; Zuo, H.; Chen, B.; Wang, R.; Ahmed, A.; Hu, Y.; Ouyang, J. Doxorubicin-loaded platelets as a smart drug delivery system: An improved therapy for lymphoma. Sci. Rep. 2017, 7, 42632. [CrossRef] [PubMed]

17. Zhang, X.; Wang, J.; Chen, Z.; Hu, Q.; Wang, C.; Yan, J.; Dotti, G.; Huang, P.; Gu, Z. Engineering PD-1-Presenting Platelets for Cancer Immunotherapy. Nano Lett. 2018, 18, 5716-5725. [CrossRef]

18. Nishikawa, T.; Tung, L.Y.; Kaneda, Y. Systemic administration of platelets incorporating inactivated Sendai virus eradicates melanoma in mice. Mol. Ther. 2014, 22, 2046-2055. [CrossRef] [PubMed]

19. Nierodzik, M.L.; Klepfish, A.; Karpatkin, S. Role of platelets, thrombin, integrin IIb-IIIa, fibronectin and von Willebrand factor on tumor adhesion in vitro and metastasis in vivo. Thromb. Haemost. 1995, 74, 282-290. [PubMed]

20. Mehta, P. Potential role of platelets in the pathogenesis of tumor metastasis. Blood 1984, 63, 55-63. [CrossRef]

21. Remiker, A.S.; Palumbo, J.S. Mechanisms coupling thrombin to metastasis and tumorigenesis. Thromb. Res. 2018, 164 (Suppl. 1), S29-S33. [CrossRef] [PubMed]

22. Sarkar, S.; Alam, M.A.; Shaw, J.; Dasgupta, A.K. Drug delivery using platelet cancer cell interaction. Pharm. Res. 2013, 30, 2785-2794. [CrossRef] [PubMed]

23. White, J.G. Platelets are covercytes, not phagocytes: Uptake of bacteria involves channels of the open canalicular system. Platelets 2005, 16, 121-131. [CrossRef]

24. Flaujac, C.; Boukour, S.; Cramer-Borde, E. Platelets and viruses: An ambivalent relationship. Cell. Mol. Life Sci. 2010, 67, 545-556. [CrossRef] [PubMed]

25. Male, R.; Vannier, W.E.; Baldeschwieler, J.D. Phagocytosis of liposomes by human platelets. Proc. Natl. Acad. Sci. USA 1992, 89, 9191-9195. [CrossRef] [PubMed]

26. Aurich, K.; Spoerl, M.C.; Furll, B.; Sietmann, R.; Greinacher, A.; Hosten, N.; Weitschies, W. Development of a method for magnetic labeling of platelets. Nanomedicine 2012, 8, 537-544. [CrossRef]

27. Jackson, S.P.; Nesbitt, W.S.; Westein, E. Dynamics of platelet thrombus formation. J. Thromb. Haemost. 2009, 7 (Suppl. 1), 17-20. [CrossRef]

28. Chatterjee, M.; Ehrenberg, A.; Toska, L.M.; Metz, L.M.; Klier, M.; Krueger, I.; Reusswig, F.; Elvers, M. Molecular Drivers of Platelet Activation: Unraveling Novel Targets for Anti-Thrombotic and Anti-Thrombo-Inflammatory Therapy. Int. J. Mol. Sci. 2020, 21, 7906. [CrossRef]

29. Dai, L.; Gu, N.; Chen, B.A.; Marriott, G. Human platelets repurposed as vehicles for in vivo imaging of myeloma xenotransplants. Oncotarget 2016, 7, 21076-21090. [CrossRef]

30. Xiong, S.; Zhao, X.; Heng, B.C.; Ng, K.W.; Loo, J.S. Cellular uptake of Poly-(D,L-lactide-co-glycolide) (PLGA) nanoparticles synthesized through solvent emulsion evaporation and nanoprecipitation method. Biotechnol. J. 2011, 6, 501-508. [CrossRef]

31. Lee, J.J.; Yu, J.Y.; Lee, J.H.; Zhang, W.Y.; Kim, T.J.; Myung, C.S.; Yun, Y.P. The protective effects of paclitaxel on platelet aggregation through the inhibition of thromboxane A2 synthase. Arch. Pharm. Res. 2010, 33, 387-394. [CrossRef] [PubMed]

32. Huang, W.; Zhang, C. Tuning the Size of Poly(lactic-co-glycolic Acid) (PLGA) Nanoparticles Fabricated by Nanoprecipitation. Biotechnol. J. 2018, 13, 1700203. [CrossRef]

33. Corbalan, J.J.; Medina, C.; Jacoby, A.; Malinski, T.; Radomski, M.W. Amorphous silica nanoparticles aggregate human platelets: Potential implications for vascular homeostasis. Int. J. Nanomed. 2012, 7, 631-639. [CrossRef]

34. Smyth, E.; Solomon, A.; Vydyanath, A.; Luther, P.K.; Pitchford, S.; Tetley, T.D.; Emerson, M. Induction and enhancement of platelet aggregation in vitro and in vivo by model polystyrene nanoparticles. Nanotoxicology 2015, 9, 356-364. [CrossRef]

35. Aurich, K.; Wesche, J.; Palankar, R.; Schluter, R.; Bakchoul, T.; Greinacher, A. Magnetic Nanoparticle Labeling of Human Platelets from Platelet Concentrates for Recovery and Survival Studies. ACS Appl. Mater. Interfaces 2017, 9, 34666-34673. [CrossRef]

36. Novakowski, S.; Jiang, K.; Prakash, G.; Kastrup, C. Delivery of mRNA to platelets using lipid nanoparticles. Sci. Rep. 2019, 9, 552. [CrossRef]

37. Knight, C.G.; Morton, L.F.; Onley, D.J.; Peachey, A.R.; Ichinohe, T.; Okuma, M.; Farndale, R.W.; Barnes, M.J. Collagen-platelet interaction: Gly-Pro-Hyp is uniquely specific for platelet Gp VI and mediates platelet activation by collagen. Cardiovasc. Res. 1999, 41, 450-457. [CrossRef]

38. Smethurst, P.A.; Onley, D.J.; Jarvis, G.E.; O'Connor, M.N.; Knight, C.G.; Herr, A.B.; Ouwehand, W.H.; Farndale, R.W. Structural basis for the platelet-collagen interaction: The smallest motif within collagen that recognizes and activates platelet Glycoprotein VI contains two glycine-proline-hydroxyproline triplets. J. Biol. Chem. 2007, 282, 1296-1304. [CrossRef]

39. Acharya, G.; Shin, C.S.; Vedantham, K.; McDermott, M.; Rish, T.; Hansen, K.; Fu, Y.; Park, K. A study of drug release from homogeneous PLGA microstructures. J. Control Release 2010, 146, 201-206. [CrossRef]

40. Matsumura, Y. Cancer stromal targeting (CAST) therapy. Adv. Drug Deliv. Rev. 2012, 64, 710-719. [CrossRef] 
41. George, J.N. Direct assessment of platelet adhesion to glass: A study of the forces of interaction and the effects of plasma and serum factors, platelet function, and modification of the glass surface. Blood 1972, 40, 862-874. [CrossRef]

42. Saelman, E.U.; Nieuwenhuis, H.K.; Hese, K.M.; de Groot, P.G.; Heijnen, H.F.; Sage, E.H.; Williams, S.; McKeown, L.; Gralnick, H.R.; Sixma, J.J. Platelet adhesion to collagen types I through VIII under conditions of stasis and flow is mediated by GPIa/IIa (alpha 2 beta 1-integrin). Blood 1994, 83, 1244-1250. [CrossRef] [PubMed]

43. Qiu, Y.; Brown, A.C.; Myers, D.R.; Sakurai, Y.; Mannino, R.G.; Tran, R.; Ahn, B.; Hardy, E.T.; Kee, M.F.; Kumar, S.; et al. Platelet mechanosensing of substrate stiffness during clot formation mediates adhesion, spreading, and activation. Proc. Natl. Acad. Sci. USA 2014, 111, 14430-14435. [CrossRef]

44. Hook, P.; Litvinov, R.I.; Kim, O.V.; Xu, S.; Xu, Z.; Bennett, J.S.; Alber, M.S.; Weisel, J.W. Strong Binding of Platelet Integrin alphaIlbbeta3 to Fibrin Clots: Potential Target to Destabilize Thrombi. Sci. Rep. 2017, 7, 13001. [CrossRef] [PubMed]

45. Nuyttens, B.P.; Thijs, T.; Deckmyn, H.; Broos, K. Platelet adhesion to collagen. Thromb. Res. 2011, 127 (Suppl. 2), S26-S29. [CrossRef]

46. Swieringa, F.; Spronk, H.M.H.; Heemskerk, J.W.M.; van der Meijden, P.E.J. Integrating platelet and coagulation activation in fibrin clot formation. Res. Pract. Thromb. Haemost. 2018, 2, 450-460. [CrossRef]

47. Allen, R.D.; Zacharski, L.R.; Widirstky, S.T.; Rosenstein, R.; Zaitlin, L.M.; Burgess, D.R. Transformation and motility of human platelets: Details of the shape change and release reaction observed by optical and electron microscopy. J. Cell. Biol. 1979, 83, 126-142. [CrossRef]

48. Weyrich, A.S.; Lindemann, S.; Zimmerman, G.A. The evolving role of platelets in inflammation. J. Thromb. Haemost. 2003, 1, 1897-1905. [CrossRef]

49. Nagy, B., Jr.; Miszti-Blasius, K.; Kerenyi, A.; Clemetson, K.J.; Kappelmayer, J. Potential therapeutic targeting of platelet-mediated cellular interactions in atherosclerosis and inflammation. Curr. Med. Chem. 2012, 19, 518-531. [CrossRef]

50. Wei, X.; Ying, M.; Dehaini, D.; Su, Y.; Kroll, A.V.; Zhou, J.; Gao, W.; Fang, R.H.; Chien, S.; Zhang, L. Nanoparticle Functionalization with Platelet Membrane Enables Multifactored Biological Targeting and Detection of Atherosclerosis. ACS Nano 2018, 12, 109-116. [CrossRef] 